PROFESIONALES Y HERRAMIENTAS PARA EL DESARROLLO LOCAL Y SUS SINERGIAS TERRITORIALES. EVALUACIÓN Y PROPUESTAS DE FUTURO IX Coloquio Nacional de Desarrollo Local del GTDL-AGE 

ANTONIO MARTÍNEZ PUCHE, XAVIER AMAT MONTESINOS, ISABEL SANCHO CARBONELL y DANIEL SANCHIZ CASTAÑO (EDS.)

\section{PROFESIONALES Y HERRAMIENTAS PARA EL DESARROLLO LOCAL Y SUS SINERGIAS TERRITORIALES. EVALUACIÓN Y PROPUESTAS DE FUTURO}

IX Coloquio Nacional de Desarrollo Local del GTDL-AGE

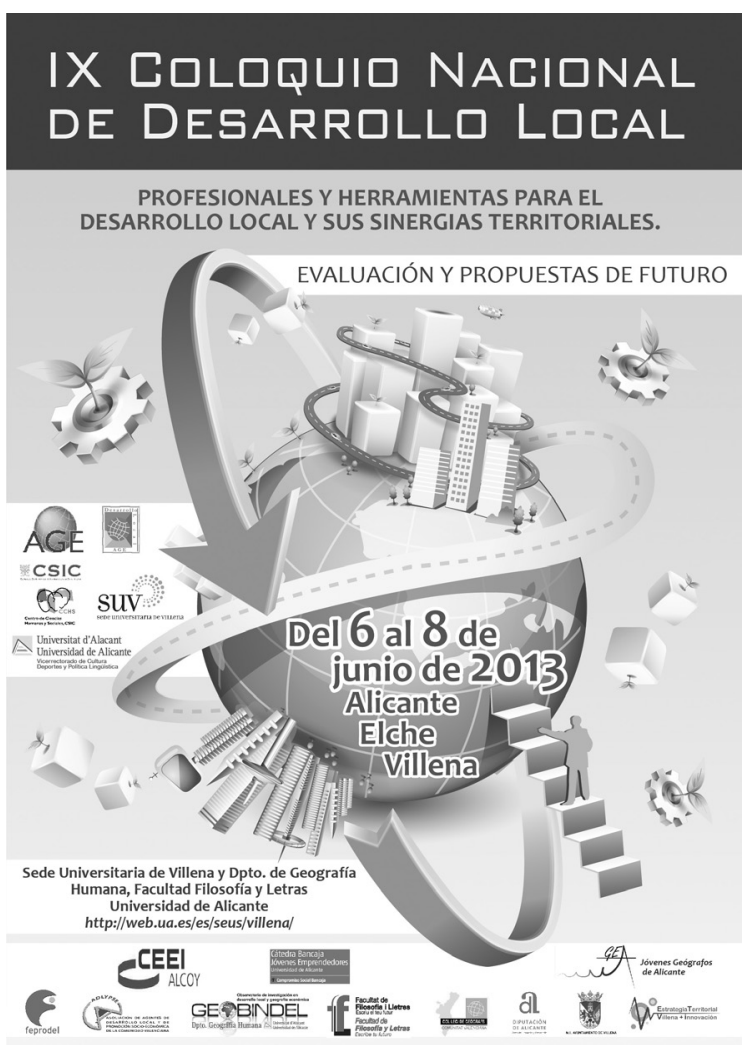


Este libro ha sido examinado y valorado por evaluadores ajenos a la Universidad de Alicante, con el fin de garantizar la calidad científica del mismo.

Publicacions de la Universitat d'Alacant

03690 Sant Vicent del Raspeig

Publicaciones@ua.es

http://publicaciones.ua.es

Telèfon: 965903480

(C) Antonio Martínez Puche, Xavier Amat Montesinos,

Isabel Sancho Carbonell y Daniel Sanchiz Castaño (eds.), 2016

(C) d'aquesta edició: Universitat d'Alacant

ISBN: 978-84-16724-00-0

Dipòsit legal: A 92-2016

Disseny de coberta: candela ink

Composició: Página Maestra (Miguel Ángel Sánchez Hernández)

Impressió i enquadernació: Guada Impresores

\section{unte \\ Unión de Editoriales
Universitarias Españolas \\ WWW.une.es
WWA}

Esta editorial es miembro de la UNE, cosa que garantiza la difusión y comercialización nacional y internacional de sus publicaciones.

Reservados todos los derechos. Cualquier forma de reproducción, distribución, comunicación pública o transformación de esta obra sólo puede ser realizada con la autorización de sus titulares, salvo excepción prevista por la ley. Diríjase a CEDRO (Centro Español de Derechos Repográficos, www.cedro.org) si necesita fotocopias o escanear algún fragmento de esta obra. 


\title{
DESARROLLO CULTURAL Y SOCIAL A PARTIR DE LOS MUSEOS LOCALES: EL CASO DEL PROYECTO DEL MUSEO DE LA VILLA DE SAX
}

\author{
Alberto Ochoa García \\ Licenciado en Historia, Universidad de Alicante \\ ochoagarcia.a@gmail.com
}

RESUMEN

Las circunstancias actuales de recesión hacen pensar en nuevos proyectos que contribuyan al desarrollo local. Los museos locales se han considerado como lugares donde se custodia, conserva, expone, investiga y difunde el patrimonio, pero, atendiendo a las nuevas tendencias museológicas, el museo presente y futuro se puede convertir en reactivador del entorno, dinamizador turístico y cultural, protector del patrimonio y en atracción para el público, desembocando en el desarrollo cultural y social y en la creación de riqueza sobre bases endógenas, fundamentadas en el concepto de resilencia: recuperar las energías del pasado para superar la crisis sobre nuevas bases de gestión.

Palabras clave: Museos, Endógeno, Patrimonio, Sociedad, Sax.

\section{CULTURAL AND SOCIAL DEVELOPMENT FROM LOCAL MUSEUMS: THE MUSEUM PROJECT CASE OF THE TOWN OF SAX}

\section{Abstract}

The current recessionary circumstances suggest new projects that contribute to local development. Local museums have been regarded as places where heritage is guarded, preserved, exhibited, researched and disseminate, but, taking into account new museological trends, present and future museums can reactivating the environment boost tourism and culture, protect heritage ant attract the public. This result in social and cultural development and wealth creation on endogenous basis which are based on the concept of resilience: recovering the energy of the past to overcome the crisis through new management strategies.

Key words: Museums, Endogenous, Heritage, Society, Sax. 


\section{INTRODUCCIÓN}

En este momento de recesión, no solamente económica, La cultura también se encuentra en crisis, pero esta puede contribuir al desarrollo local, sobre todo a través del desarrollo cultural y social que puede surgir desde ella, lo que repercutiría en la creación de riquezas endógenas. Dentro de este desarrollo, son los museos los que pueden tener un papel fundamental, siempre que superen algunos tópicos relacionados con sus funciones y se conviertan en centros de gestión integral del patrimonio.

$\mathrm{Al}$ asumir esa nueva característica, implicaría que el museo asimilara cinco nuevas funciones, como son la de reactivación del entorno, la de dinamización turística, la dinamización cultural, la custodia del patrimonio y la atracción del público. En estas funciones se observa como se ha pasado de considerar a las piezas como los elementos principales de los museos para tener como protagonista al visitante, como veremos.

En este texto se pondrá como ejemplo principal el proyecto del Museo de la Villa de Sax y se analizará, sobre todo, el caso de los museos de la provincia de Alicante, como ejemplo. Sin olvidar que aún es un proyecto, este ejemplo se utilizará para ver las posibilidades de interacción entre el museo interno y el patrimonio externo a este, convirtiendo al museo en un centro de gestión integral del patrimonio local.

\section{LOS MUSEOS LOCALES}

En ocasiones, los museos locales se presentan como entes culturales que se encuentran fuera de la vida de la población y de la realidad social de esta, considerándose como lugares donde se almacenan los restos de la historia de una población. El museo local se puede centrar excesivamente en el cumplimiento de sus funciones básicas, mostrándose como símbolo de prestigio (Espinosa y Bonmatí, 2008), más que como una institución que puede dar un servicio social, científico y cultural.

El museo se emplaza dentro de un contexto territorial, además de histórico, político y económico (Navarro, 2006), hacia el que este puede expandirse (Hernández, 1994), y gestionar bienes patrimoniales externos a él. Los museos locales se convierten, así, en centros de gestión integral del patrimonio, al tener la posibilidad de poner el valor ese patrimonio, creando productos destinados al desarrollo local (del Bien, 2010).

El visitante se puede considerar museológicamente adulto cuando sabe leer y escribir (Hernández, 2003). La Nueva Museología considera al visitante como el actor principal dentro del museo, mientras que la exposición se configura en torno a él, proporcionándole distintos puntos de vista con la incorporación de elementos museográficos de apoyo. La interactividad, es una herramienta muy importante dentro de la exposición, que debe garantizar un contenido eminen- 
temente didáctico y científico que apoye a la explicación de los conceptos y piezas expuestos, evitando la conversión de los museos en lugares de juego, evitando la disneylandización del patrimonio (Greffe, 2003).

Los museos son característicos de un cierto espacio, pero deben responder también a su entorno. A pesar de esto, los museos deben atender al panorama museístico que se encuentra a su alrededor, atendiendo a los distintos tipos de museos y a las posibilidades que tendría un nuevo museo o el desarrollo de unas nuevas funciones.

\subsection{Panorama museístico de la provincia de Alicante}

En el caso del proyecto del Museo de la Villa de Sax, pretendimos analizar el contexto museístico en el que se tendría que encajar este museo, correspondiendo este contexto a la provincia de Alicante. En esta provincia se encuentran actualmente 74 museos reconocidos por la Dirección General de Patrimonio ${ }^{1}$, aunque la Diputación Provincial de Alicante reconoce 66 ${ }^{2}$ (MARQ-2008), incorporando otros que no son reconocidos por el primer organismo. La Comunidad Valenciana cuenta con 198 museos, siendo, con datos del 2010 3 , la segunda comunidad autónoma con más museos de España, después de Castilla y León, con 203, de un total de 1530 museos en toda España. De estos 198 museos, 47 son arqueológicos (la mayor cantidad de España), 8 de arte contemporáneo, 4 de artes decorativas, 28 de bellas artes, 7 casas-museo, los mismos de ciencia y tecnología, 11 de ciencias naturales e historia natural, 1 de sitio, 15 especializados, 48 de etnografía y antropología, 13 generales y 9 de historia. De estas tipologías, adoptada por la Dirección General de Patrimonio (Fig. 1), se encuentran en la provincia de Alicante un total de 74 museos, con 32 museos arqueológicos, 20 de etnografía y antropología, 8 de ciencia y tecnología, 6 de bellas artes, 3 de ciencias naturales e historia natural, al igual que los de arte contemporáneo, y 2 casas-museo.

Al analizar algunos parámetros relacionados con la proliferación de museos, se puede ver que el tamaño de la población no corresponde con la presencia de estos, ya que la población con menos habitantes que tiene un museo, de etnografía y antropología, es El Castell de Guadalest, con 238 habitantes ${ }^{4}$, mientras que la población con más habitantes, Alicante, con 334.678, solamente tiene 3 museos. Sí que es cierto que Elche, con 230.587 habitantes, es la población que más museos posee, un total de 8. Tampoco corresponde el que la población sea un foco turístico, puesto que, por ejemplo, Benidorm no

1 http://www.cult.gva.es/dgpa/museos_c.html

2 http://www.cult.gva.es/dgpa/museos_c.html

3 Ministerio de Cultura. Estadística de Museos y Colecciones Museográficas. http://www.mcu. es/culturabase/cgi/axi

4 http://www.dip-alicante.es/documentacion/censo.asp 


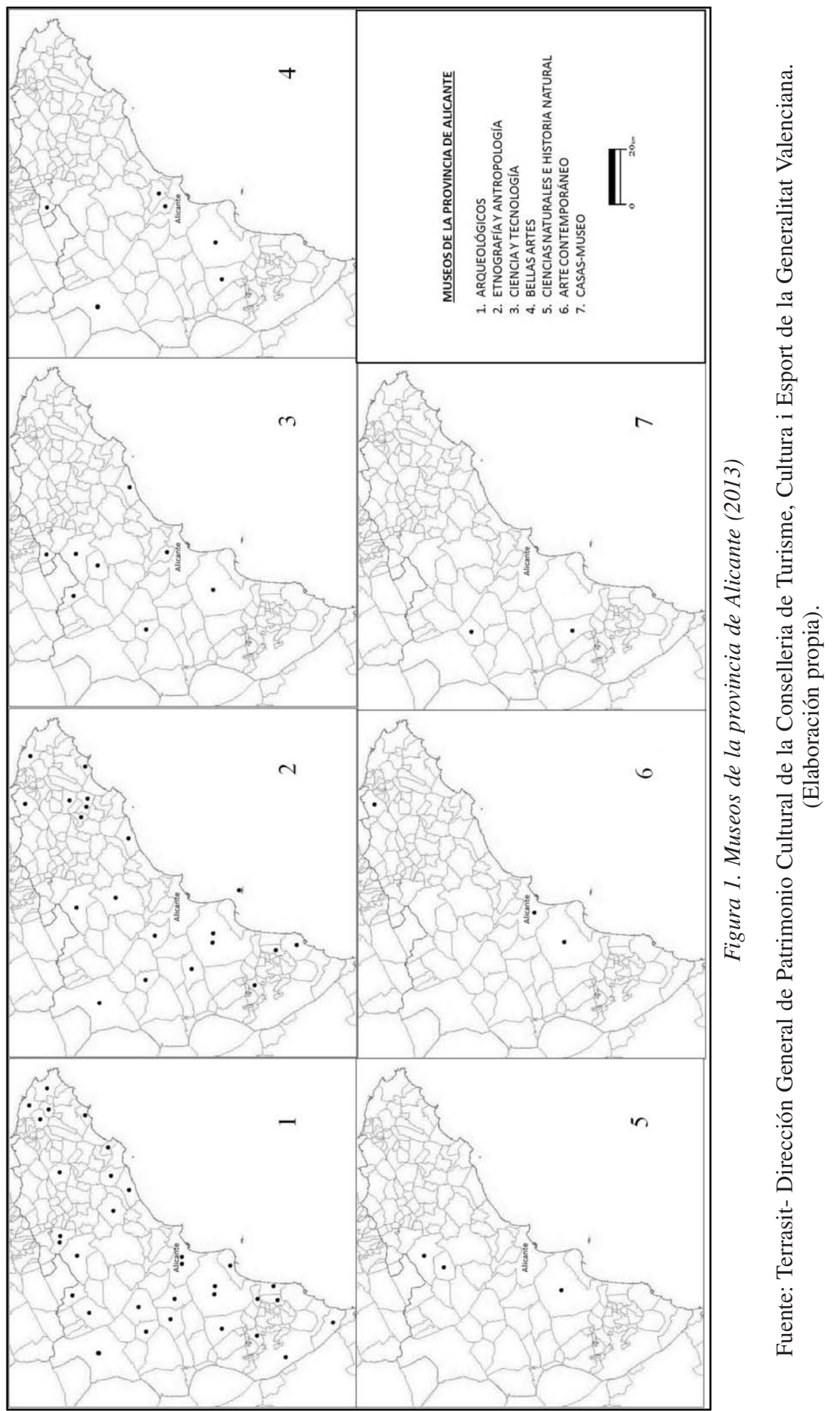


tiene museos. Entonces ¿por qué existen esos museos en los lugares donde se encuentran?

La creación de un museo depende del interés de una población de preservar su patrimonio, su memoria, ya que el museo local se nutre de su entorno. Así, mostrando algunos ejemplos, en el caso de los museos arqueológicos destacan el "José María Soler", de Villena, el "Camil Visedo Moltó" de Alcoy o el MAHE de Elche, entre otros, por la riqueza arqueológica de esos territorios. Dentro de la categoría de etnografía y antropología despuntan la Casa Museo de la Barbera dels Aragonés en Villajoyosa, el Centro de Cultura Tradicional Museo Escolar de Pusol de Elche, el Museu Alcoià de la Festa de Alcoy y el Museu de Cantarería de Agost, entre otros, por la conservación que efectúan de los oficios y vivencias locales. De ciencia y tecnología predominan entre todos el Museu Valencià del Paper de Banyeres de Mariola, el Museo del Calzado de Elda, el Museu Valencià del Joguet de Ibi y el Museu Valencià del Xocolate, también de Villajoyosa, por la conservación de los procesos productivos de elementos locales tan característicos. De la cuarta, la de bellas artes, destaca el Museo del Escultor Antonio Navarro Santafé de Villena, por la musealización de su taller y por la presencia de los modelos y procesos productivos de sus grandes monumentos. De los de la tipología de ciencias naturales e historia natural destaca el Museo Paleontológico de Elche, el MUPE, tanto por su exposición de carácter casi provincial, como por sus actividades de difusión de las etapas de la vida de la Tierra. Los tres museos de arte contemporáneo de la provincia, El Museu d'Art Contemporani d'Alacant (MACA), y los museos de Pego y Elche, son unos espacios de exposición para las tendencias locales actuales de expresión artística. Por último, de las dos casas-museo de la provincia, el Museu Pintor Julio Quesada y el C.E.A.H.M. "Alberto Sols" de Sax, sobresale el último, por haberse convertido en un centro de estudios de la localidad.

Al observar los museos de la provincia de Alicante, se puede establecer una cierta semejanza, sobre todo expositiva, donde muchos no han sabido evolucionar (Azuar, 2000). Así se podrían analizar muchos parámetros con tal de analizar la situación actual todos estos museos, pero este tema de estudio lo retomaremos en otros foros de debate. Lo que interesa ahora es analizar cómo estos tipos de museos podrían contribuir al desarrollo, a través del análisis de sus funciones.

\subsection{Las funciones del museo}

Las funciones que desarrolla el museo son las que lo identifican como tal, y las cuales se dictan en cuerpos legislativos como la ley de Patrimonio Histórico Español de 1985 o, en el caso de que nos ocupa de la provincia de Alicante, la Ley 5/2007, de 9 de febrero, de la Generalitat, de modificación de la Ley 4/1998, de 11 de junio, del Patrimonio Cultural Valenciano. Así, el museo ad- 
quiere, conserva, investiga, comunica y exhibe para fines de estudio, educación y contemplación conjuntos y colecciones de valor histórico, artístico, científico y técnico o de cualquier otra naturaleza cultural ${ }^{5}$.

Estas son las funciones tradicionales de un museo, pero la concepción del visitante y del entorno hace que otros autores las completen. De este modo, Decarli (Decarli, 2004) considera como una de las funciones del museo la reactivación del entorno local, mientras que otros (Santacana y Lloch, 2008) le adjudican también una función de dinamización turística, dinamización cultural, y de conservador del patrimonio. También se le ha otorgado una función social relacionada con la atracción de visitantes (Curtis, 2001), pero siempre con los límites ya comentados.

Así, las funciones del museo pasan de las cinco básicas, de función internamente, a incorporar cinco nuevas que hacen que gestionen también el patrimonio externo al este. Con la custodia, conservación, exposición, investigación y difusión, conjuntamente con las nuevas funciones de reactivación del entorno, dinamización turística, dinamización cultural, custodia del patrimonio, atracción de público el museo se convierte en centro de gestión integral del patrimonio local. Todas estas funciones hacen referencia al visitante, pero será en la última, la de la atracción de este, donde se hable de su importancia y de las acciones para llegar al desarrollo social de la localidad.

\section{LA REACTIVACIÓN DEL ENTORNO}

La función principal de las actuaciones en el entorno del museo tiene como finalidad la comunicación directa entre el patrimonio, el público y su territorio (Palma y Verdugo, 2004:73), además de posibilitar el acercamiento de la pieza al contexto original y la conversión del museo en el centro de interpretación de ese patrimonio.

En ese entorno se encuentran elementos patrimoniales arquitectónicos, arqueológicos, medioambientales o etnográficos que hacen que ese territorio tenga un valor concreto. Dentro del entorno se debe conocer primero lo que hay para luego darlo a conocer, por lo que una primera herramienta que podrían efectuar los museos es un catálogo de bienes y espacios protegidos, o a proteger, que puede servir para conocer el valor de todo ese patrimonio y como referencia ante cualquier actuación.

La difusión de ese patrimonio repercute en la valorización de este, ya que lo que no se da a conocer es como si no existiera para el público. Así, tras ese estudio previo del entorno, se podría intervenir con la señalización de elementos y espacios con unos paneles explicativos diseñados en cuanto a los parámetros actuales de accesibilidad y reversibilidad del soporte y del contenido.

5 Título VII, capítulo II, artículo 59.3. LEY 16/1985, de 25 de junio, del Patrimonio Histórico Español (BOE de 29 de junio de 1985). 


\subsection{La reactivación de los centros históricos}

Muchos de los museos se encuentran dentro de los centros históricos de las poblaciones, lo que puede hacer que estos intercedan en la gestión directa de los bienes que se encuentran aquí. Independientemente del tamaño del centro histórico, este posee intactas las características de la población (Taboada, 2011), aunque ha perdido el carácter de centralidad y ahora se concibe como un conjunto destinado al turismo. La rehabilitación de un inmueble de este entorno suele implicar la instalación de un museo, biblioteca, archivo u oficinas, pero es preciso el estudio de las necesidades de estos barrios, para después elegir el edificio donde se instalaría ese servicio. Esto permitiría la recuperación de la centralidad social y funcional (Ponce, 2011), lo que alejaría la posibilidad de la artificialización del centro y la pérdida de la escena urbana e implicaría a los vecinos.

Los museos actuales poseen unas ciertas necesidades espaciales para el desarrollo de sus funciones (Chinchilla, 2005), por lo que en ocasiones debe aprovechar otras instalaciones locales. En primer lugar, los museos necesitan un lugar de tratamiento y almacenaje de los bienes, por lo que pueden aprovechar almacenes municipales siempre que cumplan con las exigencias de almacenamiento. Igualmente se necesita un aparcamiento, aprovechable también por los vecinos del centro, además de zonas polivalente o bibliotecas, por lo que el uso de otros centros municipales o no puede ayudar al desarrollo de las funciones del museo.

Dependiendo de la tipología del museo, este podría contar con unos u otros profesionales que pudieran actuar en ese entorno. Suponiendo que la mayoría de museos de la provincia son arqueológicos (Fig. 1), estos poseen entre sus trabajadores de arqueólogos que pueden trabajar en la totalidad del término municipal. El establecimiento de un perímetro de protección arqueológica en los centros históricos repercutiría en el seguimiento arqueológico obligatorio de cada obra que se efectuara, donde podrían intervenir estos profesionales. Además, dentro de la posibilidad del museo de realizar el catálogo de bienes y espacios protegidos, el arqueólogo podría prospectar el término municipal.

La provincia de Alicante cuenta con una importante presencia de castillos que, más allá de su gestión conjunta a través de la Ruta de los Castillos de la Diputación Provincial de Alicante, podrían gestionarse adecuadamente desde los museos. Debemos dejar claro que gestionar un castillo no es poner un horario de visitas, sino su gestión patrimonial y su estudio con la posterior musealización, debiéndose efectuar antes de nada estudios arqueológicos, medioambientales, de accesibilidad $\mathrm{u}$ otros.

Del mismo modo en el que se intervienen en los castillos, en el entorno de los museos se pueden encontrar otros elementos ya no declarados BIC, pero sí BRL. Desde los pozos, o cavas, de nieve, a las iglesias o ermitas, hornos cerá- 
micos y de yeso, con sus correspondientes canteras, molinos, y, sobre todo, los elementos inmateriales, los oficios olvidados, las costumbres, música o festividades son bienes susceptibles de ser gestionados, desde su parte patrimonial, desde los museos.

Uno de los aspectos que también pueden gestionar los museos es el patrimonio medioambiental. La intervención en medioambiente de los museos puede propiciar la gestión de huertos urbanos, recuperación de cultivos, gestión de caminos históricos, o la realización de distintos estudios, u otros aspectos. Un elemento importante en la provincia de Alicante es el río Vinalopó, con la peculiaridad de que nace dentro de un parque natural, el de la Sierra de Mariola, y nutre a un patrimonio de la humanidad, el palmeral d'Elx. Por todo esto, en lo que eran las zonas de cultivo de rivera se pueden desarrollar actuaciones que pongan en valor este elemento y donde el museo puede intervenir. Desde la señalización hasta la reforestación de esta zona con los árboles característicos, podrían ser actuaciones que contribuyeran a formar nuevos espacios en los entornos del museo.

Todos estos aspectos en los que el museo puede intervenir implicarían, en cierto modo, la colaboración entre profesionales e instituciones con tal de favorecer un desarrollo del entorno. La puesta en marcha de estos proyectos puede no depender del museo, pero sí que es preciso que se les tengan en cuenta, ya que es un patrimonio que se debe gestionar adecuadamente.

\section{DiNAMIZACIÓN TURísTICA}

Dentro de esta función, el museo puede convertirse tanto en el centro de interpretación de la localidad como en una oficina de turismo. Los centros de interpretación no suelen tener piezas originales, pero los museos comparten con estos centros la incitación a los visitantes para que se inmiscuyan en la historia y la vida local y transmiten la necesidad de conocer esos lugares de primera mano y de conservar el patrimonio (Bertonatti, Iriani y Castelli, 2010). También puede convertirse en un centro de recepción de visitantes, donde la zona de recepción se transformaría en una oficina de turismo, y desde donde saldrían ciertas rutas turísticas. El museo debe ser consciente de sus capacidades y establecer, primero, un estudio sobre esas rutas, la puesta en valor de los bienes a visitar y la conveniente señalización del recorrido y de los bienes.

Cualquier población puede establecer unas rutas, además de que estas se pueden completar con otras poblaciones, mientras que se oferte un producto de calidad y con cierta originalidad. En el caso de Sax, por ejemplo, resaltaría la ruta del sistema defensivo del Vinalopó, la más evidente. También se pueden desarrollar rutas urbanas donde participen instituciones privadas, como ahora en la ruta del siglo XIX, donde, por ejemplo en Sax, se visitarían las viviendas, 
las plazas, puentes y la bodega cooperativa o la estación del ferrocarril. Otra ruta que se podría realizar es la del agua, visitando el río Vinalopó, las canalizaciones, los abrevaderos, acueductos, puentes, molinos hidráulicos y demás lugares relacionados con esto. Igualmente, algunas poblaciones ya desarrollan un turismo industrial que se podría completar con un turismo preindustrial, visitando los restos de esas producciones abandonadas. También se pueden realizar rutas relacionadas con el patrimonio inmaterial, como pueden ser la música o las festividades o cualquier tradición, lo que haría imprescindible la utilización de los códigos QR para la difusión de estos bienes.

Con el desarrollo de estas rutas, el museo podría verse más reflejado en la población, actuando como fomentador de las mismas y aprovechándose de estas para recibir más visitantes. Una dinamización turística así conllevaría la realización de una estrategia de márquetin y comunicación, aprovechando tanto el boca a boca (Santacana y Lloch, 2008), como los distintos medios de comunicación, donde publicitar el museo y sus actividades.

La dinamización turística desde los museos puede ser un aspecto complejo, pero todo debe estar centrado a la creación de una marca, de un producto, donde el museo se debe convertir en el centro de este.

\subsection{El producto y la marca}

El museo se puede inmiscuir en la creación de productos que agrupen distintas iniciativas locales cuyo objetivo sean la creación de riquezas desde el patrimonio. No se pueden asumir grandes proyectos como antes, pero la oferta del turismo de experiencia a través de la confección de un producto común y una marca puede ser beneficioso en muchos aspectos.

Así, podríamos establecer distintos modelos de productos y marcas que se están desarrollando en la provincia de Alicante. En el caso de Sax, hay muchos elementos a destacar, pero la importancia de que tuvo en su tiempo el que aún es el centro de la población, la plaza Cervantes, antes conocida como plaza del Parador, hacen pensar en un producto que responda a la parada y asentamiento de personas a lo largo del tiempo, todo a través del producto "Sax, una parada en el camino", donde se tendría al Museo de la Villa de Sax como centro.

En cuanto a la puesta en valor de las industrias tradicionales, cabe destacar el ejemplo de Ibi con el proyecto de la "Villa del Juguete". Esta Villa, además de surgir desde el Museu Valencià del Joguet, integraría la Fábrica Payá, una fábrica juguetera de principios del XX donde mostrarían cómo se fabricaban los juguetes que se exponen en el museo, reproduciendo y vendiendo estos. Además, pretenden crear la Casa de los Reyes Magos y el centro de pruebas del juguete, con tal de conseguir un producto de base pedagógica y educativa. Elda, por su lado, está centrada en el calzado y pretende unir tradición y actualidad en el Museo del Calzado. Al museo se le ha unido una tienda multimarca en los 
bajos del edificio ${ }^{6}$, donde se quiere aunar la historia con la actual producción local, propiciando la atracción del visitante a las instalaciones y la promoción de un producto común.

Cuanto más grande es y más patrimonio tiene una ciudad pueden ofertarse distintos productos. Así, Villena, además de la Edad de Bronce, con la propuesta de la declaración de patrimonio de la humanidad del tesoro de Villena ${ }^{7}$, y el castillo de la Atalaya, en actual proceso de puesta en valor, tiene un nuevo producto tanto turístico como de reactivación del entorno, como es un parque agrario de la huerta y la laguna ${ }^{8}$. Este elemento favorecería el desarrollo con de la recuperación de tierras y el aprovechamiento de recursos. También supondría la formación de un banco de semillas autóctonas, además de la creación de una escuela de agricultura ${ }^{9} \mathrm{y}$ de huertos urbanos.

Además de estos casos, también se encuentran localidades que han sabido fomentar su patrimonio de forma destacada. Biar, con 3695 habitantes, ha sabido atraer a los profesionales realizando un fam trip, además de conseguir que su castillo sea el único de la provincia que sea imagen de la Diputación de Alicante. Por su lado, Pinoso, a través de la fomentación de los valores de un pueblo, con el eslogan "El Pinós, l'encant de ser poble", con menos de 8000 habitantes, combina la visita a la explotación de mármol del monte Coto, la producción vinícola ecológica más importante de la Comunidad y una gastronomía reconocida y que ya ha salido en televisión.

También los destinos de sol y playa pretenden complementar esto centrándose en la cultura, como en Benidorm. Este pretende atraer a los visitantes a su historia, además de recuperar su memoria con dos museos, Boca del Calvari y $l^{\prime}$ Hort $^{10}$. El primero hablará de la historia de Benidorm desde la Edad de Bronce hasta el boom turístico y el festival de la canción. El otro museo será etnográfico, con la exposición de elementos típicos del Benidorm del siglo XIX.

Son muchos otros los productos patrimoniales que se pueden desarrollar en la provincia con el protagonismo de los museos, pero estos son los que han saltado en los últimos meses a la prensa, como elementos de desarrollo local que tienen como objetivos prioritarios la puesta en valor del patrimonio local y el desarrollo económico.

6 http://www.diarioinformacion.com/elda/2013/03/16/tienda-multimarca-abre-puertas-museocrea-gran-expectacion/1354188.html

7 http://www.diarioinformacion.com/elda/2012/03/15/villena-impulsa-unesco-declare-tesoropatrimonio-humanidad/1234125.html

8 http://www.diarioinformacion.com/elda/2012/03/28/villena-habilitara-huerto-urbano-rubial83-parcelas-partir-mayo/1238363.html

9 http://www.diarioinformacion.com/elda/2013/04/18/villena-proyecta-crear-banco-semillasespecies-autoctonas-2014/1364587.html

$10 \mathrm{http} / / / w w w . d i a r i o i n f o r m a c i o n . c o m / b e n i d o r m / 2013 / 01 / 19 /$ museos-corazon-ocio/1335286. html 


\section{DinAMiZación CUlTuRAL}

La función de dinamización cultural es la que efectúa una relación más directa con el público, combinando la función de difusión y la posibilidad de convertir al museo en un centro de organización de eventos culturales. La producción de exposiciones temporales es una forma de difusión que se puede completar con tal de que no solamente el museo efectúe eventos en su interior, sino que este tenga una repercusión en los eventos que se efectúen fuera de él, siempre que tengan que ver con el patrimonio que él gestiona. Las exposiciones temporales y los cursos son esenciales para el buen funcionamiento de la institución museística, ya que esto le permite profundizar en temas de investigación o presentar resultados de la misma, dinamizar el museo y motivar al público a acudir tanto a la actividad como al museo.

La función de dinamización cultural repercutiría en una relación con distintas instituciones locales y extralocales que, en apariencia, es posible que no tengan mucha relación con un museo. Instituciones culturales como grupos de teatro, bandas de música, centros educativos o asociaciones diversas de la localidad, o hasta restaurantes pueden establecer una relación con el museo local a la hora de desarrollar esta función. El museo local, tal y como tienen otras instituciones culturales, debe tener una programación de eventos que den vida al contenido de mismo.

Además de las actividades didácticas, el museo puede enfocar su actividad también hacia el público que desee disfrutar del museo de otra forma. La realización de talleres es una forma de dinamización cultural que permite que, con referencia a lo expuesto en el museo, los entendidos locales puedan enseñar a efectuar los elementos referentes a los oficios olvidados, a las técnicas artísticas o a otros aspectos relacionados con el museo. Talleres de arqueología, de cerámica, de enología, de etnografía, de música, de testimonios orales, de investigación histórica, del desarrollo de las funciones del museo o de hasta restauración o lectura de textos del archivo histórico, o de cualquier tema, se podrían desarrollar en el museo.

Una propuesta de dinamización cultural es la celebración de los días mundiales. Dependiendo de la temática del museo, con cualquier elemento o pieza destacada se podrían celebrar unos u otros días mundiales. En el caso del proyecto del Museo de la Villa de Sax se han establecido como los más interesantes el día mundial de la mujer trabajadora (8 de marzo), el día del árbol (23 de abril), el día mundial del agua (15 de marzo), el día mundial de la voz (17 abril) y, por supuesto, el día de los museos (18 de mayo) o, ya no mundial, el día de la música valenciana ( 29 de abril).

Son muchas las posibilidades que tiene el museo de contribuir a esa dinamización cultural que se enfocaría hacia el público local, pero estos son solamente unos ejemplos ilustrativos de lo que ya han hecho otros museos. La difusión es primordial para darle vida al museo. 


\section{PRotección DEL PATRIMONIO}

El museo no es, como estamos observando, un simple espacio de exposición, sino que debe acogerse a una cierta legislación. Esa legislación establece las formas de actuación tanto en el funcionamiento del museo como en cuanto a la gestión del patrimonio exento a él. Comenzando por la ley de Patrimonio Histórico Español, esta desarrolla las funciones básicas del museo y hace se refiere al ingreso de los fondos arqueológicos, Título V artículo 42.2. En cuanto a la legislación de la Comunidad Valenciana, la Ley 5/2007, de 9 de febrero, de la Generalitat, de modificación de la Ley 4/1998, de 11 de junio, del Patrimonio Cultural Valenciano, habla de los mismos aspectos que la ley nacional, incorporando, artículo 73.1 del Título IV, la aceptación de fondos privados en el museo, además de crear el sistema Valenciano de Museos, Título IV artículo 70, y los requisitos para ser reconocido como museo, en el artículo 71.

Sobre la legislación específica sobre los museos, el Reglamento de Museos Estatales, en el Capítulo VI, desarrolla las funciones que debe desempeñar cada uno de los departamentos del museo y, en el Capítulo VII, establece las características del horario de visita a los mismos. También es preciso atender a las normas de conducta y las prácticas profesionales para los museos y su personal de Consejo Internacional de Museos, el ICOM, en su código de deontología, donde hablan de las características del edificio, artículo 1, y de las funciones de cada profesional, artículo 1.11 y siguientes. En el artículo 2 habla de las políticas a llevar a cabo en torno a las piezas. También interesa su artículo 4, donde se habla de la necesidad de la función educativa de los museos. También en la legislación valenciana, la Orden de 6 de febrero de 1991, de la Conselleria de Cultura, Educación y Ciencia, regula el reconocimiento de museos y colecciones museográficas permanentes de la Comunidad Valenciana, y establece los requisitos que debe cumplir un museo.

En cuanto al patrimonio, interesa el Decreto 571/1963, que establece la obligación por parte de los municipios de conservar el patrimonio. Además, la Ley de Patrimonio Valenciano establece las categorías de Bien de Interés Cultural, para los elementos importantes para el conjunto de la autonomía, y los Bienes de Relevancia Local, en cuanto a su importancia a nivel local o comarcal. Estas categorías establecen todos los criterios de declaración y protección de los bienes, pero, en el segundo caso, también el Decreto 62/2011, de 20 de mayo, del Consell, establece las categorías de los bienes declarados BRL.

Otras leyes como la 16/2005, de 30 de diciembre, Ley Urbanística Valenciana, dictan criterios para la conservación del patrimonio. En el artículo 38 especifican los criterios de elaboración de los Planes Especiales, para la creación de reservas patrimoniales, y los Catálogos de Bienes y Espacios Protegidos, definiendo los criterios de conservación de los bienes. Además en el artículo 49 establece la delimitación de los centros históricos y los criterios de actuación en los mismos, además de que implica a los ayuntamientos en la rehabilitación de los bienes, según el artículo 212. 
Son muchos las leyes que pueden hacer referencia a un museo o al patrimonio local, por lo que aquí solamente hemos analizado las leyes principales. Igualmente, no solamente existen leyes generales, sino también específicas que declaran cierto elemento patrimonial con tal de protegerlo. Todas estas leyes las tiene que tener en cuenta el museo con tal de proteger y gestionar correctamente el patrimonio.

\section{Atracción DEL PÚBLICO Y DESARROLlo SOCIAL}

Hemos observado cómo el museo ya no se puede concebir como un elemento aislado de la población, ya que contribuye al desarrollo cultural a través de sus funciones. También hemos visto cómo el visitante ahora pasa a considerarse el protagonista de la gestión del museo, lo que contribuye al desarrollo social. Todas las acciones que se han propuesto hacen referencia al visitante, sobre todo a su diversión, la que resultaría de la asistencia del visitante a las distintas actividades del museo y la atención que recibiría aquí. Para conseguir esa diversión el museo debe atender a varias acciones.

El museo, se debe convertir en un lugar de recreo, estudio, creatividad, o descubrimiento, por lo que debe de ser accesible a todos, por lo que no sólo hay que atender a la accesibilidad física, sino también a la intelectual. La accesibilidad física implica ciertos problemas cuando el museo reutiliza un inmueble anterior. Rampas, marcas en el suelo, sistema braille y demás no garantizan la accesibilidad completa al museo. Hay que atender también a la accesibilidad intelectual, donde el museo debe interpretar todo correctamente, garantizando el acceso al patrimonio de las personas con capacidades distintas, utilizando el mismo lenguaje entre el creador de la pieza, la pieza y el visitante (Hervías, 2011), lo que permitirá un acceso democrático al contenido. Existe el problema del idioma, lo cual algunos solucionan poniendo códigos QR, cuando no se dispone de espacio.

El visitante puede participar en el museo desde muchas perspectivas, pero una interesante es a través de las páginas web 3.0, donde se pueden tomar decisiones y crear conocimiento. Sería una herramienta de contacto entre el visitante y el museo donde la web se perfila como una extensión del mismo. Subir fotografías, tanto antiguas como actuales, con el debido registro de los datos, puede producir nuevo material para el museo, igual que los comentarios o artículos que puedan escribir los usuarios.

Además de todos estos aspectos, los museos, y la cultura en general, aumentan la cohesión social, integrando a toda la población en un mismo discurso, creando un interés por el patrimonio local, su recuperación y conservación, dialogando con el patrimonio y consiguiendo posicionar la población hacia el exterior y, sobre todo, creando empleo (Maceira, 2008). Ya en la realización del proyecto serían necesarios arquitectos, o distintos profesionales de la construcción, además de diseñadores gráficos, informáticos, profesionales de 
los distintos elementos museográficos de apoyo, museólogos y museógrafos, además de los que deben hacer el discurso museográfico. Ya formado el museo, dentro del personal interno se necesita un director, además de un conservador, un administrativo, y, especialistas en la disciplina de cada museo. En los puestos básicos debería estar también un conserje-recepcionista, pero, al convertirse en oficina de turismo, debería tener preparación en turismo. En cuanto al desarrollo de funciones externas al museo, también sería necesario un guía, y para las funciones de difusión se necesitaría una persona con conocimientos en publicidad y relaciones públicas. Se pueden desarrollar otros puestos de trabajo relacionados con el museo, pero, si el museo es municipal, algunas de estas funciones dependerán de otros centros. Además, en momentos puntuales, se pueden contratar otros profesionales.

Externamente al funcionamiento del museo se pueden desarrollar otros comercios y servicios que puedan, en determinado momento, colaborar con el museo. El mecenazgo y el patrocinio pueden beneficiar en muchos aspectos tanto al museo como a esos servicios, además de que con el éxito de las actividades externas al museo se podrían desarrollar otros servicios relacionados con la hostelería u otros campos de venta de recuerdos o complementarios a las actividades que desarrolle el museo.

Como hemos podido observar, un museo es una apuesta por el desarrollo local desde distintos aspectos. El desarrollo cultural y social es posible con el desarrollo de proyectos culturales. La recesión ha impedido que muchos de los proyectos se llevaran a cabo, pero no es preciso elaborar un proyecto entero. Se puede comenzar con la redacción de los distintos proyectos e informes y con las primeras actuaciones preliminares. Hay que tener claro que todo lleva su esfuerzo, pero puede beneficiar mucho a una población, creando puestos de trabajo que favorezcan a los vecinos. El futuro comienza hoy, por lo que hay que trabajar para que este beneficie al desarrollo local, y el museo tiene mucho que aportar.

BIBLIOGRAFÍA

AZUAR RUIZ, R. (2000): "Museos alicantinos ante el año 2000. El Museo Arqueológico y la Galería Provincial de Bellas Artes". Canelobre, Revista del Instituto Alicantino de Cultura "Juan Gil-Albert". № 41-42.

BERTONATTI, C., IRIANI, O. Y CASTELLI, L. (2010): "Los centros de interpretación como herramienta de conservación y desarrollo". Boletín de Interpretación $n^{o} 23$. Asociación para la Interpretación del Patrimonio. Pp. 21-26.

CHINCHILLA GOMEZ, M., (2005): Criterios para la elaboración del plan museológico. Madrid. Ministerio de Cultura, Subdirección de Bellas Artes y Bienes Culturales, Subdirección General de Museos Estatales. 
CURTIS, W. (2001): "Introducción sobre los museos", Jornadas de arquitectura contemporánea. La arquitectura de los museos. Pp. 20-25.

DECARLI, G. (2004): Un museo sostenible: museo y comunidad en la preservación activa de su patrimonio. Oficina de la UNESCO para América Central.

DEL BIEN SÁNCHEZ, T. (2010): "Gestión del patrimonio cultural de la ciudad de Toro: Casos prácticos y alternativas". El canto de la Musa. Revista digital de humanidades. Asociación Cultural Musical Jesús López Cobos. $\mathrm{N}^{\mathrm{o}} 1$.

ESPINOSA RUIZ, A. Y BONMATÍ LLEDÓ, C. (2008): “Cómo no construir un museo por el tejado". Boletín de Interpretación $n^{\circ} 19$. Asociación para la Interpretación del Patrimonio. Pp. 12-14.

GREFFE, X. (2003):” ¿Es el patrimonio un incentivo para el desarrollo?”. PH: Boletín del Instituto Andaluz del Patrimonio Histórico, n 42, pp. 43-50.

HERNÁNDEZ HERNÁNDEZ, F. (1994): Manual de Museología. Biblioteconomía y documentación. Ed. Síntesis.

HERNÁNDEZ HERNÁNDEZ, F. (2003): El museo como espacio de comunicación. Ediciones TREA.

HERVÍAS BEORLEGUI, J. J. (2011): "Interpretación del patrimonio en museos arqueológicos y de bellas artes”. Boletín Interpretación $n^{\circ} 24$. Asociación para la Interpretación del Patrimonio. Pp. 10-12.

MACEIRA OCHOA, L. (2008): "Los públicos y lo público. De mutismos, sorderas, y de diálogos sociales en museos y espacios patrimoniales". en Arrieta, I. (coord.) Participación ciudadana, patrimonio cultural y museos: entre la teoría y la praxis. Universidad del País Vasco. Pp. 38-60.

MARQ- MUSEO ARQUEOLÓGICO DE ALICANTE (2008): Museos de Alicante. MARQ (coord.). Diputación de Alicante. 82 p.

PALMA MARTOS, L. Y VERDUGO SANTOS, J., (2004):'Economía de la cultura, museo y territorio. Una aproximación a la realidad andaluza". Encuentro internacional sobre museo y territorio. Siena en Sevilla. Madrid. Junta de Anadalucía Consejería de Cultura. 2004. Pag. 61-96

PONCE HERRERO, G. (2011): "Desarrollo turístico en centros históricos". Gestión y dinamización del comercio en centros históricos. AEDIFICATIO. Pp.39-41.

SANTACANA I MESTRE, J. Y LLOCH MOLINA, N. (2008): Museo Local, la cenicienta de la cultura. Ediciones TREA.

TABOADA ESPINELLA, D. M. (2011): "Importancia de los centros históricos en las ciudades contemporáneas". Gestión y dinamización del comercio en centros históricos. AEDIFICATIO. Pp. 8-9.

Anuario de estadísticas culturales 2012. Ministerio de Educación, Cultura y Deporte. Subdirección General de Estadística y Estudios, 2012. http:// www.mcu.es/estadisticas/MC/NAEC/index.html 